\title{
Audiência de Custódia Como Alternativa de Combate à Superlotação Carcerária em Petrolina - PE
}

\section{Jaiza Sammara de Araújo Alves}

Doutoranda em Direito Penal pela Universidad de Buenos Aires. Especialista em Direito Penal e Processual Penal pela Uniseb e em Psicologia Jurídica pela Facape. Professora dos cursos de Direito da Faculdade de Ciências Aplicadas e Sociais de Petrolina (Facape) e da Universidade do Estado da Bahia - campus III - Juazeiro; coordenadora do Núcleo de Práticas Jurídicas da Facape. Professora da Pós-Graduação em Direito Municipal e da Pós-Graduação em Psicologia Jurídica da Facape. Orcid: <http://orcid.org/0000-0002-7436-9906>. jaizasam@yahoo.com.br

\section{Ana Flávia de Souza Ribeiro}

Advogada. Bacharel em Direito pela Faculdade de Ciências Aplicadas e Sociais de Petrolina. anafsribeiro95@gmail.com

Entre os vários problemas que o Brasil vem enfrentando nos últimos anos, certamente a superlotação carcerária é um deles. Durante muito tempo o poder público procurou encontrar alternativas de combate a esta problemática, contudo nenhuma resposta foi dada de forma satisfatória. Assim, em 2015, o Conselho Nacional de Justiça, por meio da Resolução n. 213, disciplinou acerca da Audiência de Custódia, buscando uma redução no número de prisões provisórias, cujos números são bastante altos nos Brasil. Desse modo, o presente artigo tem por objetivo tratar sobre a Audiência de Custódia, buscando, por intermédio de dados estatísticos, analisar as contribuições que esta audiência tem trazido em âmbito nacional, bem como no Estado de Pernambuco, porém enfocando, principalmente, a cidade de Petrolina - PE, na qual a Penitenciária Doutor Edvaldo Gomes também vem sofrendo diante da superlotação carcerária. Para a consecução da pesquisa foi adotada a metodologia da pesquisa qualitativa, em que foram utilizados dados primários e secundários, bem como a pesquisa quantitativa, em que foram analisados dados estatísticos colhidos na Comarca de Petrolina, uma vez que houve a constatação de que a Audiência de Custódia é um mecanismo muito importante para a redução do cárcere provisório naquela comarca.

Palavras-chave: Audiência de Custódia. Comarca de Petrolina - PE. Prisão provisória. Resolução n. 213. Superlotação carcerária.

\section{CUSTODY AUDIENCE AS AN ALTERNATIVE OF COMBATING CARCERARY SUPERLOTATION IN THE CITY OF PETROLINA - PE}

\section{ABSTRACT}

Out of the various problems that Brazil has been experiencing on the last years, prison overcrowding is certainly one of them. For many years the government tried to find alternatives to combat this problem, but no response was given satisfactorily. Thus, in the year 2015 the National Council of Justice through of a Resolution n. 213, disciplined about the Audience of Custody, seeking a reduction in the number of provisional prisons, whose numbers are very high in Brazil. The purpose of this paper is to analyze the Audience of Custody, searching through statistical data, the contributions that this audience has brougth to the national level and the State of Pernambuco, as well as to the city of Petrolina, in which the Penitentiary Dr. Edvaldo Gomes has also suffered with overcrowding of the prison system. In order to achieve the research, the methodology of the qualitative research was used, in which primary and secondary data were used, as well as the quantitative research, in which statistical data were collected from Petrolina county, where it was verified that the Audience of Custody is a very important mechanism for the reduction of the temporary jail in this region.

Keywords: Audience of custody. City of Petrolina. Provisional prison. Resolución n. 213. Overcrowding.

SUMÁRIO

1 Introdução. 2 Evolução Histórica do Sistema Prisional. 3 Superlotação Carcerária Brasileira: visão geral. 4 Superlotação Carcerária em Pernambuco. 5 Superlotação Carcerária em Petrolina. 6 Audiência de Custódia. 7 Audiência de Custódia em Petrolina - PE. 8 Considerações Finais. 9 Referências. 


\section{Democracia}

\section{Introdução}

A pena privativa de liberdade nem sempre vigorou, passando somente a ser institucionalizada em meados do século 18. Assim, antes de haver o cerceamento da liberdade do condenado, eram aplicadas a ele penas extremamente cruéis e desumanas, com o intuito de se obter, principalmente, o sofrimento físico daquele que havia cometido um ato delituoso. Ressalte-se que a partir do lluminismo houve uma modificação na maneira de pensar a aplicação das penas (GRECO, 2015), e desse modo, o suplício foi substituído pela prisão, tendo surgido em vários locais sistemas prisionais, cada um com suas características específicas que refletiam a realidade de cada país que havia adotado a privação de liberdade como pena.

Dessa forma, o presente artigo tem por objetivo, inicialmente, versar sobre a superlotação carcerária, tratando sobre a evolução das penas privativas de liberdade, pontuando a passagem das penas cruéis até a sua humanização, bem como apresentar as características dos sistemas prisionais, analisando a maneira como o sistema prisional brasileiro foi influenciado por estas características.

Posteriormente será tratada a superlotação carcerária nos presídios brasileiros, problema este que vem afetando o país há muito tempo, tendo em vista que os números de criminalidade estão aumentando cada vez mais. Ressalte-se que a superlotação carcerária, com as suas rebeliões e massacres, foram os principais assuntos noticiados no início do ano de 2017, sinalizando que este é um problema que necessita de maior atenção das autoridades públicas. Desse modo, faz-se necessário analisar os fatores que levaram à superlotação do cárcere, a fim de que sejam investigadas maneiras de tentar solucionar esta problemática que tanto afeta a realidade brasileira.

É importante ressaltar que, no ano de 2015, visando a combater a superlotação carcerária trazida pelas prisões provisórias, o Conselho Nacional de Justiça (CNJ) instituiu a Audiência de Custódia, ressaltando-se que este instrumento já estava institucionalizado por meio de tratados internacionais (Convenção Americana de Direitos Humanos, Pacto Internacional sobre Direitos Civis e Políticos) dos quais o Brasil é signatário. Inicialmente, porém, a Resolução n. 213 havia sido firmada apenas entre o CNJ e o Tribunal de Justiça do Estado de São Paulo, e passou a vigorar a partir de fevereiro de 2015. O Estado de Pernambuco passou a adotar a Audiência de Custódia a partir de agosto de 2015, por meio da Resolução n. 380 do Tribunal de Justiça do Estado de Pernambuco.

Diante do exposto, com este estudo objetiva-se também analisar a Audiência de Custódia, investigando como ocorre a sua realização e quais são os resultados que este instrumento vem trazendo em âmbito nacional e estadual (Pernambuco) e principalmente na Comarca de Petrolina - PE, que, tal qual a maioria das Comarcas do país, também vem sofrendo com as mazelas da superlotação do sistema prisional.

Para a consecução do presente trabalho foi utilizada a pesquisa qualitativa, por meio da análise de dados primários, como a legislação brasileira e resoluções; e dados secundários colhidos da revisão bibliográfica, em que foram utilizados vários autores expoentes no tema. Fora realizada também a pesquisa quantitativa, com a finalidade de coleta de dados estatísticos na Penitenciária Dr. Edvaldo Gomes, localizada na cidade de Petrolina - PE, bem como nas 
Varas Criminais da mesma Comarca em que são realizadas as Audiências de Custódia, buscando, por meio dos números, analisar se, efetivamente, este instrumento está contribuindo para a redução da população carcerária na cidade supramencionada.

\section{Evolução Histórica do Sistema Prisional}

Um homem, diante de uma igreja, obrigado a pedir perdão publicamente; atenazado nos braços, coxas, mamilos, pernas e barriga; esquartejamento do corpo por quatro cavalos. Essas cenas caracterizam a época da imposição de penas cruéis e desumanas, aplicadas pelos soberanos, àqueles que estavam sendo acusados de praticar crimes. $O$ homem da cena descrita anteriormente tem por nome Robert-François Damiens, acusado de atentar contra a vida do Rei Luís XV (FOUCAULT, 2013). São essas as cenas que demonstram como era realizada a execução pública na França, tendo em vista que as penas cruéis e infamantes perduraram até meados do século 18.

Foi no mesmo século que a pena privativa de liberdade passou a vigorar, ocorrendo aqui uma mudança de perspectiva da pena, pois ela não é mais voltada para o castigo do corpo. Acerca do tema, afirma Mably, apud Foucault (2013, p. 21): "Que o castigo, se assim posso exprimir, fira mais a alma do que o corpo". A pena privativa de liberdade surge, então, para acabar com as punições corporais que os soberanos aplicavam aos acusados, sendo estas, muitas vezes, extremamente cruéis, de maneira que, por meio da privação da liberdade de locomoção visava-se amenizar o sofrimento físico do condenado.

Assim, o sistema prisional surge como alojamento para aqueles acusados que estão cumprindo pena privativa de liberdade, e desde então, esse sistema tem sofrido algumas mudanças em suas características.

A primeira forma de sistema prisional de que se tem conhecimento foi o chamado Sistema Pensilvânico, popularmente conhecido por celular, tendo surgido na Filadélfia no ano de 1790 e tinha como principais características o isolamento total do encarcerado, sem nenhum contato com o mundo exterior e nem com os outros detentos; não havia possibilidade de trabalho e/ou estudo; ademais, havia o estímulo do arrependimento mediante a leitura da Bíblia. Tal sistema foi bastante criticado, tendo em vista que não possibilitava a readaptação social do preso (GRECO, 2014a). Damásio de Jesus (2008, p. 249), acerca do referido sistema, preleciona: "Utiliza-se o isolamento celular absoluto, com passeio isolado do sentenciado em um pátio circular, sem trabalhos ou visitas, incentivando-se a leitura da bíblia". Desta forma, o objetivo maior desse sistema era levar o acusado a se arrepender do ato criminoso praticado, posto que este era considerado pecado.

Após o sistema celular tem-se o sistema auburniano, quando em 1816 foi autorizada a sua construção nos Estados Unidos da América, mais precisamente na cidade de Auburn - Nova York. Aqui, diferentemente do sistema anterior, já era possível o trabalho em grupos ou individual, contudo os detentos não poderiam se comunicar, tendo de se submeter ao silêncio absoluto (BITENCOURT, 2016). Esse sistema também ficou conhecido por "silent system", justamente pelo fato de haver a incomunicabilidade entre os presos, para que assim pudessem chegar à disciplina. A crítica maior a esse sistema ocorreu pelo fato de que nele eram aplicados castigos excessivamente cruéis, colocando os presos muitas vezes num "estilo de vida militar" para alcançar a disciplina (BITENCOURT, 2016). Posteriormente foi criado o sis- 
tema progressivo, surgido na Inglaterra em meados do século 19. A finalidade desse sistema era justamente a diminuição gradativa da intensidade da pena. De uma maneira mais clara, o sistema progressivo era composto por três etapas: a primeira etapa conhecida como período de prova, pois o detento tinha sua liberdade cerceada totalmente (característica do sistema pensilvânico); na segunda etapa era permitido o trabalho em grupo, contudo era necessário o silêncio absoluto, bem como o isolamento noturno (características do sistema auburniano); a terceira e última etapa era algo semelhante ao que hoje é chamado de liberdade condicional, que era uma fase intermediária para que o preso tivesse direito à liberdade total (GRECO, 2014). Ainda acerca desse sistema, leciona o professor Cezar Roberto Bitencourt:

A essência deste regime consiste em distribuir o tempo de duração da condenação em períodos, ampliando-se em cada um os privilégios que o recluso pode desfrutar de acordo com sua boa conduta e o aproveitamento demonstrado do tratamento reformador. Outro aspecto importante é o fato de possibilitar ao recluso reincorporar-se à sociedade antes do término da condenação. A meta do sistema tem dupla vertente: de um lado pretende constituir um estímulo à boa conduta e à adesão do recluso ao regime aplicado, e, de outro, pretende que este regime, em razão da boa disposição anímica do interno, consiga paulatinamente sua reforma moral e a preparação para a futura vida em sociedade" (2016, p. 169).

Já o sistema progressivo irlandês foi levado para a Irlanda por Walter Crofton, com uma mudança do modelo original (sistema progressivo inglês), haja vista que no novo sistema foi introduzida mais uma fase, que consistia numa etapa em que se permitia ao acusado o trabaIho fora do presídio com o recolhimento noturno, o qual era chamado "semiliberdade", constituindo esta uma fase anterior à liberdade condicional (MIRABETE, 2011). Percebe-se que esse sistema aparentava ser bastante eficaz, visto que corroborava para que o sentenciado pudesse ser readaptado e ressocializado.

Ressalte-se que o sistema prisional brasileiro sofreu influências do sistema progressivo, pois foi esse o modelo adotado no Brasil (com algumas mudanças) e em outros países civilizados (MIRABETE, 2011). É importante salientar que o sistema progressivo no Brasil passou por algumas evoluções. Em dias atuais, por exemplo, a progressão de regime consiste na passagem de um regime mais gravoso a um mais flexível, estando essa progressão pautada em requisitos objetivos e subjetivos. Ressalte-se que, no Brasil, há três regimes de cumprimento de pena: fechado, semiaberto e aberto. Dessa forma, o livramento condicional não constitui um quarto regime de cumprimento de pena, constituindo, assim, outro benefício que também possui os seus requisitos.

Quanto aos regimes de cumprimento de pena, no regime fechado, o agente deverá cumpri-lo em estabelecimento de segurança máxima ou média, de acordo com o artigo 33, $\S 1$, alínea "a" do Código Penal, e para que ele seja o regime inicial de cumprimento da pena, é necessário que a punição em concreto pela qual o agente foi condenado seja superior a 8 (oito) anos. Já no regime semiaberto, que segundo a legislação vigente deveria ser cumprido em colônia agrícola, industrial ou similar, nos termos do artigo 33, §1으, alínea "b", o quantum da pena em concreto deve ser superior a 4 (quatro) anos e não exceda a 8 (oito) anos. Por fim 
o regime aberto, em que a pena imposta na sentença deverá ser igual ou inferior a 4 (quatro) anos, deve ser cumprido em casas de albergados, ou estabelecimentos similares, conforme preceitua o artigo 33, $\S 1$ 1a alínea " $c$ " do Código Penal.

Ainda tratando acerca da progressão de regime, para que o preso obtenha esse direito, é necessário o cumprimento de $1 / 6$ da pena, quando se tratar de prática de crime comum; e cumprimento de $2 / 5$ ou $3 / 5$ da pena quando se tratar de crime hediondo e equiparado (réu primário e reincidente, respectivamente). Além desse requisito, é necessário que o detento apresente um bom comportamento, atestado pelo diretor do estabelecimento prisional. É mister também ressaltar que, em alguns casos, poderá o juiz requerer o exame criminológico se for necessário, bem como o parecer da Comissão Técnica de Classificação (CTC), ${ }^{1}$ para que assim o agente consiga a progressão para um regime menos rigoroso. Tais requisitos, porém, passaram a ser facultativos a partir da entrada em vigor da Lei n. 10.792/2003 (MIRABETE, 2011).

Essa progressividade das penas, ou progressão de regime, baseia-se em um direito constitucional do preso, que disciplina o princípio da individualização da pena, para garantir e resguardar a dignidade da pessoa humana (artigo 5ㅇ, inciso XLVI, CF/88). Dessa forma, o Estado ao aplicar a pena e ao adotar a forma do sistema progressivo, objetiva que o preso não só seja punido pelo crime cometido, mas que tenha a oportunidade de voltar a viver em comunidade, por meio da reintegração à sociedade.

Outro benefício adotado pelo Brasil é o livramento condicional, o qual concede a liberdade antecipada ao preso, contudo é necessário o preenchimento dos requisitos elencados no artigo 83 do Código Penal Brasileiro. Ainda acerca do tema, aduz Nélson Hungria apud E. Magalhães Noronha:

O livramento condicional é, em relação ao condenado, inquestionavelmente um direito: direito ao benefício, à recompensa da liberdade antecipada. Ao cometer o crime no regime de uma lei penal que concede o livramento, surge para o réu a obrigação de sofrer a pena que lhe venha a ser imposta, mas também simultaneamente, o direito de, ao fim de certo tempo, e dadas as condições prefixadas na lei, obter que lhe seja dispensado o efetivo cumprimento do restante da pena (2004, p. 291).

Desse modo, para ter o sentenciado direito a tal benefício, faz-se imprescindível o preenchimento de algumas condições (objetivas e subjetivas), previstas em lei. Assim, poderá o juiz conceder o livramento condicional nos casos em que a pena seja igual ou superior a 2 (dois) anos, desde que: cumpra mais de $1 / 3$ da pena, quando não reincidente em crime doloso e tenha bons antecedentes; já se o condenado for reincidente em crime doloso é necessário o cumprimento de mais da metade da pena; ademais, é necessária a comprovação, durante a execução da pena, de que o condenado teve comportamento satisfatório, bom desempenho no trabalho e que está apto para prover a própria subsistência, mediante trabalho honesto; além disso, deverá o sentenciado reparar o dano, exceto nos casos em que for impossível a reparação; cumprir mais de $2 / 3$ da pena, nos casos de cometimento de crime hediondo e equiparado, e o agente não for reincidente específico em crimes dessa natureza. Ainda vale elucidar que nos casos de cometimento de crime doloso, com violência ou grave ameaça,

A Comissão Técnica de Classificação, existente em todo estabelecimento, será presidida pelo diretor e composta, no mínimo, por 2 (dois) chefes de serviço social, 1 (um) psiquiatra, 1 (um) psicólogo e 1 (um) assistente social, quando se tratar de condenado à pena privativa de liberdade (artigo 70 da LEP). 


\section{Democracia}

a concessão do benefício do livramento condicional estará condicionada à constatação de condições pessoais de que o condenado não voltará a delinquir; tudo isso como preceitua o artigo 83 do Código Penal e seu parágrafo único.

Neste diapasão, percebe-se que a principal finalidade ao se adotar o sistema progressivo, bem como o livramento condicional, mesmo que de forma diversa das versões originais, é fazer com que os condenados regressem ao convívio social antes do término do cumprimento das suas penas, posto que ambos os benefícios almejam a ressocialização dos indivíduos que, apesar de terem praticado e sido condenados por delitos, conseguem, desde que se encaixem nos requisitos legais, uma abreviação da sua permanência no cárcere.

\section{Superlotação Carcerária Brasileira: visão geral}

Nos dias atuais um dos grandes problemas do sistema prisional brasileiro reside na superlotação carcerária. E essa problemática que o Brasil tem enfrentado vem afrontando direitos constitucionais dos indivíduos encarcerados. É importante elucidar que o simples fato de indivíduos terem sua liberdade cerceada pelo Estado não enseja a perda de determinados direitos, por exemplo, a dignidade da pessoa humana.

A cada ano a população carcerária cresce de forma desenfreada no Brasil, e isso pode ser corroborado por dados trazidos pelo Conselho Nacional de Justiça - CNJ - em pesquisa realizada no ano de 2017 (CONSELHO..., 2017a). Neste estudo constatou-se que a quantidade de presos que o Brasil possuía até 2017 era 654.372, ou seja, um aumento de 5,17\% em relação à pesquisa realizada em 2014, que apontava um número de 622.202 presos (DEPARTAMENTO..., 2014).

Ressalte-se que no ano de 2014 o Brasil vinha ocupando a 4a posição no ranking de países com maior população carcerária, perdendo apenas para os Estados Unidos da América, China e Rússia, como se depreende de dados publicados pelo Infopen. ${ }^{2}$

Tabela 1 - População carcerária mundial

\begin{tabular}{|c|c|c|c|}
\hline Posição & País & População Prisional & Ano de Referência \\
\hline $\mathbf{1}$ & Estados Unidos da América & $\mathbf{2 . 2 1 7 . 0 0 0}$ & 2013 \\
\hline $\mathbf{2}$ & China & $\mathbf{1 . 6 5 7 . 8 1 2}$ & 2014 \\
\hline $\mathbf{3}$ & Rússia & $\mathbf{6 4 4 . 2 3 7}$ & 2015 \\
\hline $\mathbf{4}$ & Brasil & $\mathbf{6 2 2 . 2 0 2}$ & 2014 \\
\hline $\mathbf{5}$ & Índia & $\mathbf{4 1 8 . 5 3 6}$ & 2014 \\
\hline $\mathbf{6}$ & Tailândia & $\mathbf{3 1 4 . 8 5 8}$ & 2015 \\
\hline $\mathbf{7}$ & México & $\mathbf{2 5 5 . 1 3 8}$ & 2015 \\
\hline $\mathbf{8}$ & Irã & $\mathbf{2 2 5 . 6 2 4}$ & 2014 \\
\hline $\mathbf{9}$ & Turquia & $\mathbf{1 7 6 . 2 6 8}$ & 2015 \\
\hline $\mathbf{1 0}$ & Indonésia & $\mathbf{1 7 3 . 7 1 3}$ & 2015 \\
\hline
\end{tabular}

Fonte: DEPARTAMENTO..., 2014.

O Infopen é o Levantamento Nacional de Informações Penitenciárias. É o banco de dados, o qual contém informações de todas as unidades prisionais brasileiras. 
Ainda acerca da superlotação carcerária, que consiste em um aumento exagerado no número de presos, somado à carência de vagas no sistema prisional brasileiro, tem gerado um caos que há algum tempo o poder público tenta resolver, contudo sem obter muito sucesso, visto que a população carcerária vem aumentando bastante a cada ano.

Outro dado trazido pelo Infopen versa sobre a população carcerária no ano de 2014 e a quantidade de vagas, demostrando, assim, que há uma grande deficiência no número de vagas nos presídios brasileiros.

Tabela 2 - A situação carcerária brasileira em 2014

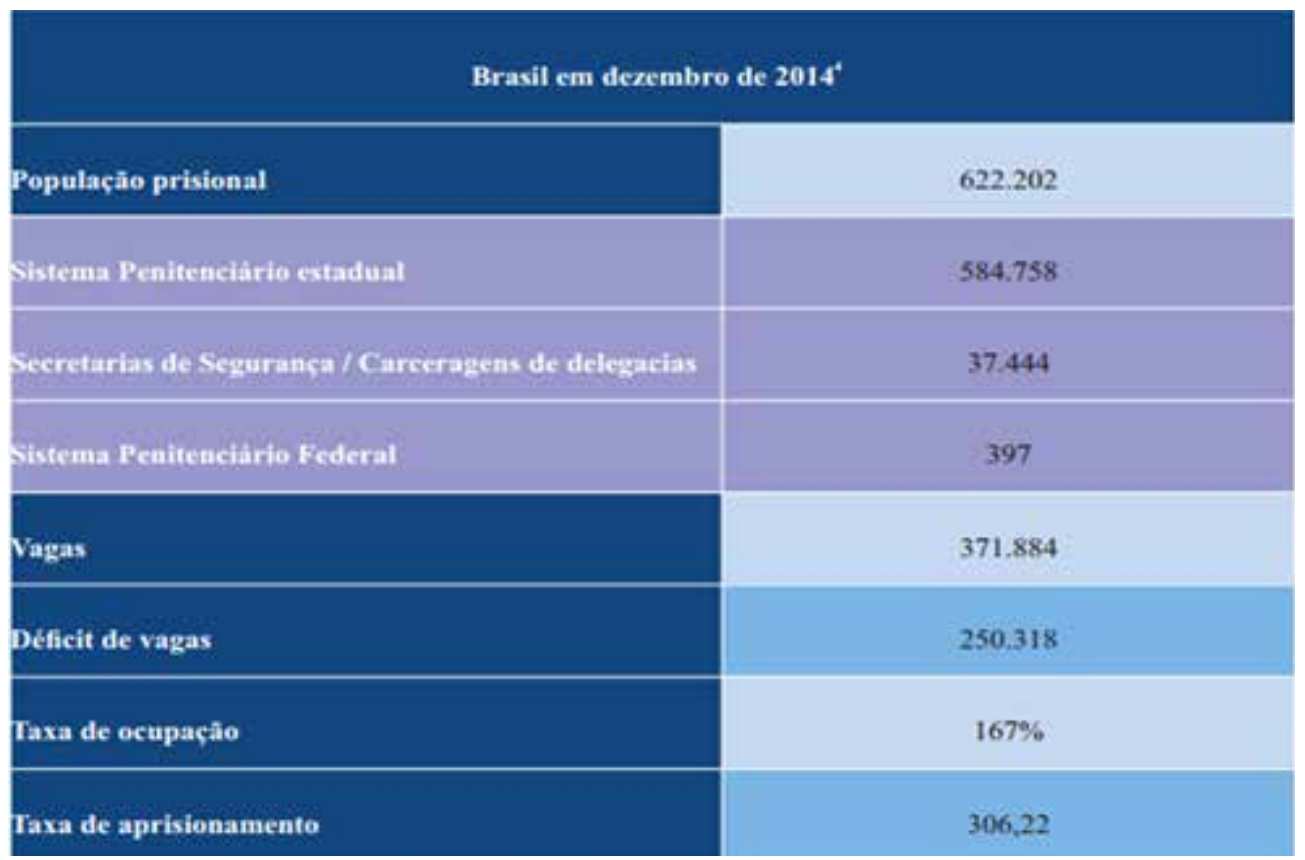

Fonte: DEPARTAMENTO..., 2014.

Diante desta realidade, surgem os questionamentos: O que leva a esse aumento desenfreado do número de presos? Estão as penas cumprindo suas finalidades?

As penas, segundo Fernando Capez (2014, p. 379-380), são uma sanção imposta pelo Estado, que consiste na restrição de um bem jurídico, tendo por objetivo: a retribuição punitiva ao agente; readaptar ou ressocializar e, por fim, prevenir novas transgressões (pela coerção/intimidação).

Diante do que preleciona tal doutrinador (CAPEZ, 2014, p. 380), é nítido que, de fato, o Estado tem se preocupado mais em punir seus agentes pelos delitos praticados, deixando para último plano o papel ressocializador da pena (que visa a reintegrar esses delinquentes ao convívio social), e o papel inibitório das penas (visando a uma diminuição de práticas criminosas).

Destarte, pode-se afirmar que a ineficácia da pena é um fator importante para o caos que o país está enfrentando com a superlotação carcerária. O gráfico a seguir mostra a "evolução" da população prisional no Brasil, confirmando assim a premissa de que as penas não cumprem com seus objetivos, haja vista o grande número de presos. 


\section{Democracia}

Gráfico 1 - A evolução da população prisional no Brasil entre os anos 2000 e 2014

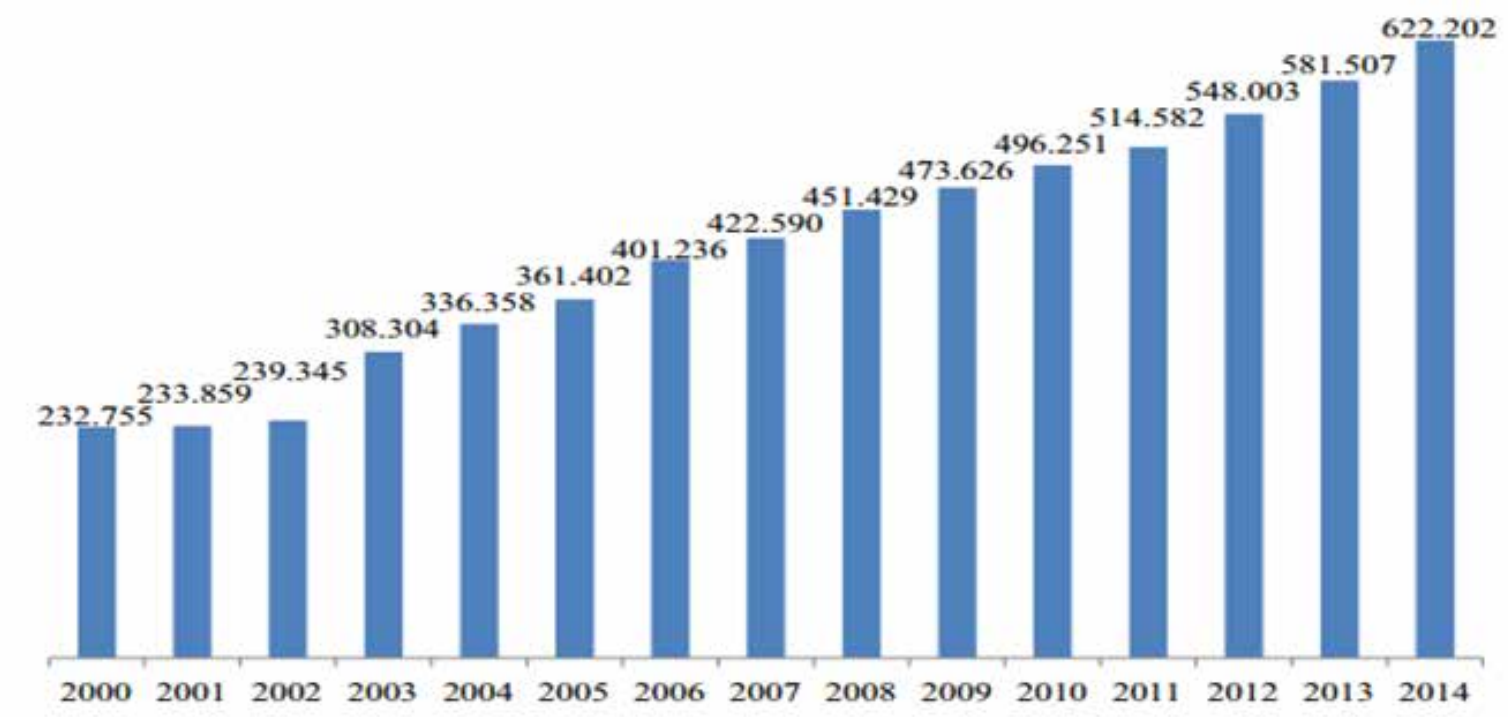

Fonte: Relatórios Estatísticos do Sistema Prisional Brasileiro - anos 2000 a 2013.

Outro fator que tem contribuído para a superlotação carcerária são os casos de detenções de presos provisórios, ou seja, indivíduos que ainda não foram julgados definitivamente, posto que dos 654.372 presos no Brasil, aproximadamente 33\% são provisórios. Diante do que disciplina a Constituição Federal, são estes presumidamente inocentes, pois ainda não foram julgados, bem como não receberam uma sentença condenatória, no entanto ainda continuam detidos, à espera da finalização do seu processo, o que se dá por meio de uma sentença, que pode, inclusive, demorar anos para ser proferida.

Ainda acerca do tema, o Pacto Internacional sobre Direitos Civis e Políticos elenca em seu artigo 9o, item 3:

Qualquer pessoa presa ou encarcerada em virtude de infração penal deverá ser conduzida, sem demora, à presença do juiz ou de outra autoridade habilitada por lei a exercer funções judiciais e terá o direito de ser julgada em prazo razoável ou de ser posta em liberdade. A prisão preventiva de pessoas que aguardam julgamento não deverá constituir a regra geral, mas a soltura poderá estar condicionada a garantias que assegurem o comparecimento da pessoa em questão à audiência, a todos os atos do processo e, se necessário for, para a execução da sentença (ORGANIZAÇÃO..., 1969).

Com relação ao tema prisão e liberdade, assevera o professor Guilherme de Souza Nucci que "deve-se ressaltar constituir a liberdade a regra, no Brasil; a prisão a exceção" (2014, p. 26). Mesmo, contudo, diante dessa premissa constitucional e doutrinária, de que a prisão deve ser a "ultima ratio da extrema ratio", na pratica não é o que vem ocorrendo, haja vista o grande número de pessoas que são encarceradas antes mesmo do trânsito em julgado da sentença penal condenatória, ou da ratificação da condenação em segunda instância.

A superlotação carcerária é um grande problema para o sistema prisional brasileiro, e é a partir dela que surgem outros problemas. Pode-se destacar um em especial, que são as rebeliões e massacres, assunto que ganhou muita repercussão no início do ano de 2017, por 
exemplo, em Manaus (AM), que deixou em torno de 67 mortos; em Boa Vista (RR) que levou à morte aproximadamente 33 pessoas; e na Penitenciária de Alcaçuz, Nísia Floresta (RN), em que ocorreram 26 mortes $(\mathrm{G} 1,2017)$.

Desta forma, essas rebeliões tiveram, possivelmente como fator preponderante, o número de presos acima do limite que o estabelecimento prisional poderia comportar.

\section{Superlotação Carcerária em Pernambuco}

O Estado de Pernambuco, no que no que se refere à superlotação carcerária, segundo dados estatísticos, vem ocupando a segunda posição acerca da deficiência de vagas, perdendo apenas para o Estado do Amazonas.

Segundo os dados trazidos pelo Infopen, por meio do levantamento realizado no ano de 2014, Pernambuco contava com uma população carcerária de 26.809 presos. É importante elucidar que a quantidade de vagas disponíveis era de apenas 11.308, como se depreende do gráfico a seguir:

Gráfico 2 - População carcerária das unidades da Federação

\begin{tabular}{|c|c|c|c|c|c|c|}
\hline wi & $\frac{45}{4}=$ & $\frac{1}{28}=$ & $\frac{47}{4}$ & $\frac{1}{4}$ & 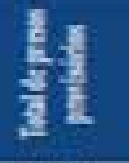 & $\frac{14}{12}$ \\
\hline Af & 4741 & 81.97 & 730k & ltwin & 1134 & $7 n_{1} \times 17 m$ \\
\hline A1: & 8.474 & ITnen & स्था & FNo74 & $+37=$ & 5natipty \\
\hline NWI & A mint & 23 wan & 470 & sumpin & 355 & fintrith \\
\hline A1" & 2.501 & 19.27 & $14=4$ & $17+7 \mathrm{~h}$ & Akit & 93.3576 \\
\hline ines & 10,011 & 10,1 & Bast & 142th & andind & nlowhth \\
\hline 4:1: & $21 \mathrm{~F}+4$ & $3+4+3$ & $1 \mathrm{i}+7 \mathrm{~h}$ & I Buth & 10407 & 414,4974 \\
\hline int & 14.405 & 40,11 & W20 & $20 \times 4 h$ & 4010 & 2k,054h \\
\hline $1 \mathrm{~A}$ & if nuld & 12.43? & 13572 & 1247. & Z1BR & 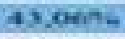 \\
\hline atas & 15.471 & \pm 1.380 & AoY? & 17244 & Friti & 4h-min \\
\hline ADA & 6.7403 & 47 & 41249 & isfotin & $4+40 i$ & natutith \\
\hline Aute: & nisuz & 24.56 & Jroths & $167+4$ & 30712 & anjovise \\
\hline SDh & $1,4,0147$ & $3+0.45$ & towh & Jaknth & $4 i \leq 1$ & 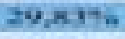 \\
\hline Mir & 10,138 & 91.96 & strins & 17244 & 5072 & $53,457 \mathrm{~h}$ \\
\hline $1+4$ & $12 \times 27$ & 1.5.tin & 7RENG & Iformin & finsog & AH. alme \\
\hline IPII & 104-45i & tholl? & 74114 & Inth & 2014 & 37,0576 \\
\hline IPI: & Finsury & Th, & I i. $1 \mathrm{~min}$ & $277 \mathrm{~F}$ & 1.7xat? & $50.674 h$ \\
\hline$H$ & $3.1 \mathrm{kz}$ & 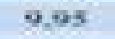 & 2271 & $1+34=$ & $1 \mathrm{in}=$ & shyotit \\
\hline IHII & Jentin & 25,27 & IKITA & 15174 & Iftit & s.1.104t \\
\hline iny & $+40,-101$ & $94.4+4$ & $3 \times 114$ & 14174 & thasy & $41+2174$ \\
\hline $\mathrm{FW}$ & $7.4 \times 4$ & $37,+1$ & tump: & istotin & Iftuil & $31,2 \times 4=$ \\
\hline int & 17.9147 & Imp_thi & 6150 & $2 \mathrm{~m}^{2} \mathrm{~h}$ & 0527 & 52.777 \\
\hline mill & I. Fint & MAl is: & Iathas & I म17 & HAH & Ppifirto \\
\hline$M F$ & 26,125 & Is, om & $712 \times 7$ & 1124 & uJat & 34.7176 \\
\hline Fe & if, & 24.4 & $1204 \mathrm{~s}$ & I tirtin & +156 & $2 r .454 h$ \\
\hline $\mathrm{HII}$ & 4053 & Tow1 & 7479 & $1+274$ & $7.5 \mathrm{~K}$ & S4.4k7th \\
\hline 9 & $+24+643$ & 14 매 & $1.7 \mathrm{HaH}$ & 1fHeth & nimh & स4+174. \\
\hline Twis & 5.772 & If, +5 & 27oi & 25174 & +1172 & $73, n 34$ in \\
\hline Dritha & H. & 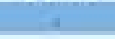 & 771. & $915=$ & 46 & 11.4AFin \\
\hline Mrasul & watson & Mone & $271 \mathrm{km1}$ & 14774 & Ityphok & $\log _{4} 1 \times 4$ \\
\hline
\end{tabular}

Fonte: DEPARTAMENTO..., 2014. 


\section{Democracia}

Assim, é nítida a deficiência de vagas que o sistema prisional brasileiro vem enfrentando, principalmente no Estado de Pernambuco. Desta forma, há uma superlotação carcerária de aproximadamente $137 \%$ no referido Estado, constituindo este um número assustador, pois percebe-se que a construção de presídios e ocasionalmente o surgimento de vagas não têm surtido muito efeito, visto que o número de presos cresce em uma proporção maior que a de número de vagas.

É imperioso destacar que o número de presos provisórios é fator que corrobora bastante para essa atual crise do sistema prisional pernambucano. Em Pernambuco, segundo levantamento de dados realizado pelo CNJ no ano de 2017, a quantidade de presos provisórios corresponde a $41,8 \%$ em relação ao total de detentos, como se pode depreender do gráfico a seguir; e de acordo com dados do ano de 2014, a população carcerária deste referido Estado atingiu a quantidade de 26.809 presos. Assim, tomando como base esses dois dados (de 2014 e 2017), pode-se de forma aproximada concluir que a quantidade de provisórios é de cerca de 11.206 presos.

\section{Gráfico 3 - Percentual de presos provisórios nas unidades da Federação}

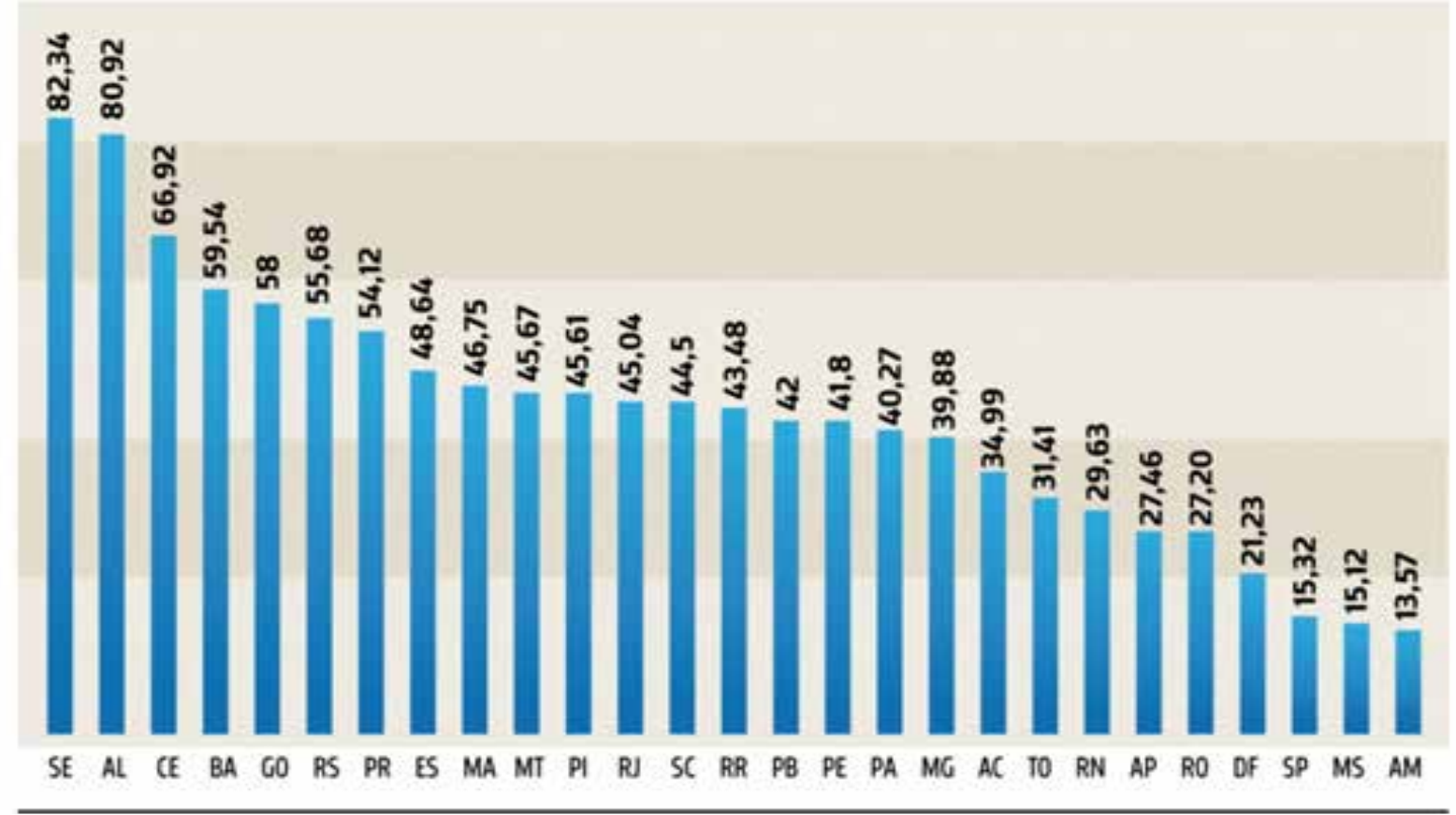

Fonte: CONSELHO..., 2017a.

É importante destacar que, além do fato de Pernambuco possuir um número considerável de presos provisórios, é o Estado também que lidera o ranking de tempo médio em dias de prisão provisória, ou seja, os presos provisórios ficam cerca de 974 dias custodiados, mesmo sem uma sentença penal condenatória.

Deste modo, é nítido que o número de presos provisórios tem contribuído para a crise do sistema prisional. Ademais, o que colabora também para a superlotação é o tempo em que esses presos provisórios, cuja sentença penal condenatória ainda não transitou em julgado, ficam custodiados. 
Acerca do tema, o Conselho Nacional de Justiça, em pesquisa, traz um dado assustador, posto que Pernambuco lidera o ranking de Estados em que há maior quantidade de prisões a título provisório. No gráfico a seguir pode-se confirmar a afirmação:

\section{Gráfico 4 - Tempo de prisão provisória no Estado de Pernambuco}

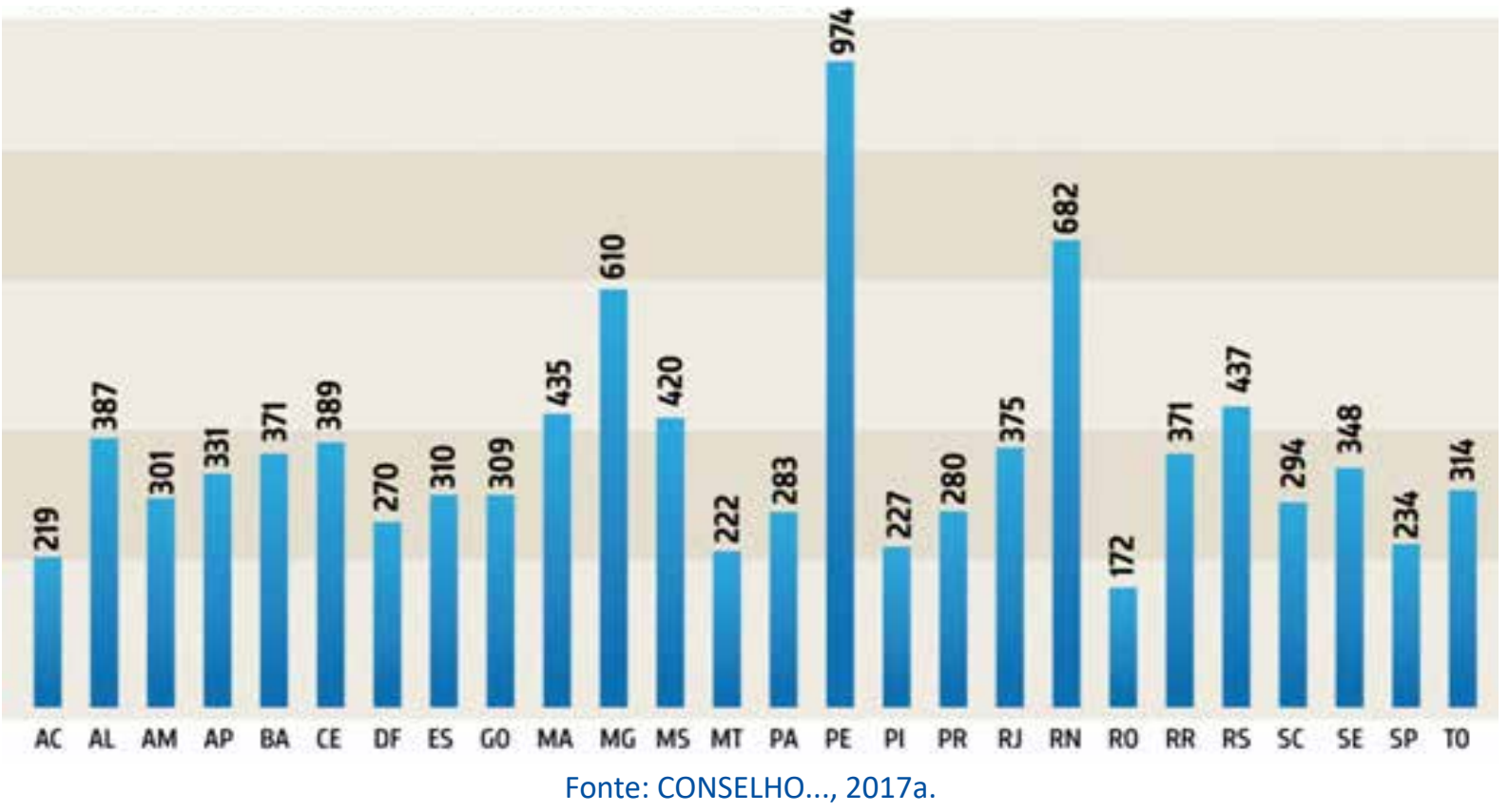

Deste modo, Pernambuco tem deixado pessoas presas provisoriamente por cerca de 974 dias, ou seja, aproximadamente 3 anos, sem haver uma sentença condenatória definitiva. Assim percebe-se a necessidade de uma Justiça mais célere, para que haja o julgamento desses presos provisórios.

\section{Superlotação Carcerária em Petrolina}

A cidade de Petrolina, localizada no sertão Pernambucano, tem contribuído para as estatísticas de superlotação carcerária no referido Estado, haja vista que na Penitenciária em estudo, a PDEG, ${ }^{3}$ há mais presos do que a quantidade de vagas disponíveis.

É mister salientar que em estudo de campo realizado na referida Penitenciária, constatou-se que algumas exigências que a Lei de Execuções Penais preconiza não estão sendo atendidas por tal repartição, entre elas: a questão que a Penitenciária não se limita apenas aos presos condenados a cumprirem inicialmente em regime fechado, como há também a possibilidade de ser cumprida a pena nesse estabelecimento em regime semiaberto. Desta forma, em desacordo com o que preceitua o artigo 87 da Lei de Execuções Penais em seu caput, que afirma: "a penitenciária destina-se ao condenado à pena de reclusão, em regime fechado". Da mesma forma, está havendo o descumprimento do que foi determinado no artigo $33, \S 1$ o do Código Penal, que aduz: Considera-se: a) regime fechado a execução da pena em estabelecimento de segurança máxima ou média; b) regime semiaberto a execução da pena em colônia agrícola, industrial ou estabelecimento similar; c) regime aberto a execução da pena em casa de albergado ou estabelecimento adequado.

PDEG é a Penitenciária Doutor Edvaldo Gomes, situada na cidade de Petrolina - PE. 


\section{Democracia}

Outro aspecto a ser destacado é a superlotação nas celas. A Lei de Execuções Penais, em seu artigo 88, aduz: "O condenado será alojado em cela individual que conterá dormitório, aparelho sanitário e lavatório". Nesse estabelecimento prisional, contudo, os presos não estão alojados em celas individuais, porém em celas que, em sua maioria, destinam-se a um grupo de pessoas.

Tratando ainda sobre o tema da superlotação nas celas, para corroborar com a premissa de que de fato existe essa problemática na PDEG, a tabela a seguir servirá como base:

Tabela 3 - Quantidade de vagas e de reclusos na Penitenciária Dr. Edvaldo Gomes - Petrolina - PE

\begin{tabular}{|lc|}
\hline \multicolumn{1}{|c|}{ PENITENCIÁRIA DR EDVALDO GOMES } \\
\hline CAPACIDADE & 775 RECLUSOS \\
\hline $\begin{array}{l}\text { TOTAL DE PRESOS } \\
\text { REEDUCANDOS }\end{array}$ & 1.282 \\
\hline
\end{tabular}

Fonte: Dados colhidos na Penitenciária Dr. Edvaldo Gomes - Petrolina - PE (PDEG). Adaptado pelo autor.

Diante dos dados expostos, percebe-se que há uma superlotação de aproximadamente 65\% na Penitenciária Dr. Edvaldo Gomes. Assim sendo, tal fato vem afrontando princípios e garantias constitucionais. O Sistema Prisional ao não cumprir com a exigência trazida pela LEP, acerca da individualização da cela, está em desarmonia com o que preceitua também a Constituição Federal, em seu artigo 5o, inciso XLIX, que afirma: "assegurado aos presos o respeito à integridade física e moral". Dessa forma, o que se vê nos estabelecimentos prisionais como um todo é o desrespeito à integridade física do preso, por haver uma deficiência de vagas no sistema prisional; celas superlotadas, condições muitas vezes sub-humanas.

Frise-se que não é pelo fato de terem sua liberdade cerceada, que faz com que os encarcerados percam alguns direitos e garantias, como a integridade física e moral. Sobre esse tema o artigo 38 do Código Penal Brasileiro assevera: "O preso conserva todos os direitos não atingidos pela perda da liberdade, impondo-se a todas as autoridades o respeito à sua integridade física e moral" (BRASIL, 1941). Assim, cabe ao Estado, detentor do jus puniendi, atentar para a efetivação das garantias dos presos.

Ressalte-se que dos 1.282 presos detidos na Penitenciária Dr. Edvaldo Gomes, há um percentual que se refere aos presos provisórios, que estão aguardando julgamento.

Gráfico 5 - Porcentagem de presos definitivos e provisórios na Penitenciária Dr. Edvaldo Gomes - Petrolina - PE

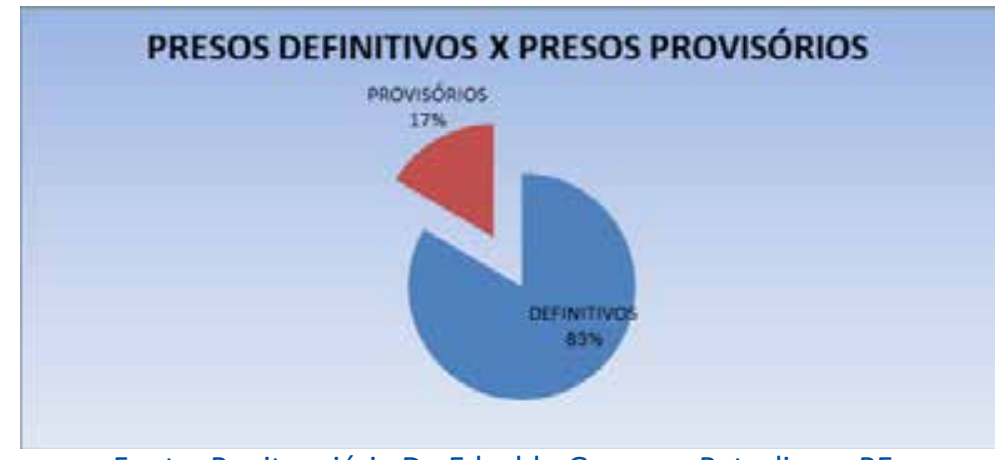

Fonte: Penitenciária Dr. Edvaldo Gomes - Petrolina - PE. 
Assim, a quantidade de presos provisórios na referida penitenciária é de 212 presos, constituindo aproximadamente $17 \%$ do total de detentos dessa Penitenciária. Diante do que já foi demonstrado em gráficos anteriores, acerca dos dados de presos no Estado de Pernambuco, percebe-se que Petrolina, mesmo apresentando uma superlotação carcerária, não conta com uma quantidade tão elevada de presos provisórios, haja vista que Pernambuco conta com mais de 11 mil presos cautelares.

Surge então a indagação: O que tem contribuído para esse número relativamente baixo de presos provisórios na Penitenciária Dr. Edvaldo Gomes, se comparado a outras instituições penais? Como resposta, pode-se depreender que há alguns fatores que têm colaborado para isso, entre eles o trabalho desse sistema penitenciário, juntamente com os órgãos da Defensoria Pública e Varas Criminais dessa Comarca. Assim, o número de presos tem diminuído e a tendência é continuar diminuindo, contudo a superlotação ainda é um problema que essa Penitenciária vem enfrentando, e precisa ser solucionado.

\section{Audiência de Custódia}

Constatando-se uma violação a direitos fundamentais da população carcerária, justamente pelo fato da superlotação do sistema prisional brasileiro, o Partido Socialismo e Liberdade, por meio da Arguição de Descumprimento de Preceito Fundamental (ADPF 347), requereu o reconhecimento da violação desses direitos dos presos. O Supremo Tribunal Federal assim reconheceu parcialmente a cautelar solicitada na referida ADPF (SUPREMO..., 2015).

A decisão do Supremo se resumiu em determinar que os juízes e os Tribunais de Justiça passassem a realizar a audiência de custódia, no prazo máximo de 90 (noventa) dias, garantido assim o direito do preso de ser levado à presença do juiz em até 24 (vinte e quatro) horas após o flagrante (SUPREMO..., 2015).

Além da decisão dada pelo Supremo nessa ADPF, houve o julgamento da Ação Direta de Inconstitucionalidade ADI 5.240, proposta pela Associação de Delegados contra ato normativo do Tribunal de Justiça de São Paulo. A decisão da referida ADI disciplina a constitucionalidade da apresentação do preso à presença da autoridade competente (SUPREMO..., 2015).

Respeitando-se assim as duas decisões do Supremo Tribunal Federal, o Conselho Nacional de Justiça - CNJ - em uma parceria firmada com o Tribunal de Justiça do Estado de São Paulo, por meio da Resolução de número 213/2015, disciplinou acerca do instituto da Audiência de Custódia, como mecanismo de ajuda a combater a superlotação carcerária no Brasil, e assim resguardar os direitos fundamentais dos encarcerados que estavam sendo violados. A Resolução entrou em vigor apenas no ano de 2015 , sendo assim um instituto relativamente novo (CONSELHO..., 2017a). Vale frisar, contudo, que a referida audiência é recente somente no que concerne a sua prática, pois este "direito" já se encontrava previsto em tratados internacionais, como o famoso Pacto de San José da Costa Rica e o Pacto Internacional sobre Direitos Civis e Políticos (ANDRADE, 2015).

De uma maneira geral, a Audiência de Custódia consiste em levar o preso em flagrante, à presença de um juiz (até 24 horas após o flagrante), com a finalidade de observar a possibilidade de aplicação de outras medidas diversas da prisão, ou saber se o agente foi preso mediante tortura, maus-tratos, etc. O próprio termo "custódia" remete-nos à proteção, ou seja, 


\section{Democracia}

nela será analisado se os direitos fundamentais desses presos estão sendo garantidos. Vale salientar que tais direitos, mesmo já estando disciplinados nos tratados internacionais antes do ano de 2015, somente obtiveram maior aplicação no Brasil a partir desse ano, tendo em vista que não consistia numa prática comum (CONSELHO..., 2016).

É importante mencionar que o Conselho Nacional de Justiça, ao tratar da Audiência de Custódia, visava a torná-la uma ferramenta para colaborar com a diminuição da superlotação carcerária no Brasil (CONSELHO..., 2016). Dessa forma, a partir do ano de 2015 tais audiências passaram a ser realizadas em todos os Estados da Federação e no Distrito Federal (CONSELHO..., 2016).

Frise-se que é na Audiência de Custódia que o juiz irá analisar se será necessária a conversão da prisão em flagrante em preventiva, ou se no caso em questão pode-se aplicar uma medida diversa do encarceramento, como o relaxamento da prisão ou a concessão da liberdade provisória (Resolução n. 213, 2015).

Acerca do procedimento e outros detalhes da Audiência de Custódia, encontram-se disciplinados na Resolução de n. 213 de 15/12/2015. Em suma, o preso em flagrante deverá ser levado à presença de autoridade competente no máximo em 24 horas após o flagrante, devendo neste momento haver a presença do representante do Ministério Público e de Defensor Público, se este não possuir advogado constituído, como disciplina o artigo 4음 da referida Resolução. Ressalte-se que, para garantir o direito do preso, a audiência será realizada sem a presença dos agentes que foram responsáveis pela prisão ou pela investigação, e antes do flagranteado ser levado à presença do juiz em Audiência de Custódia deverá ser oportunizado a ele o encontro prévio e reservado com seu advogado ou defensor público.

Sendo assegurado este direito e o preso em flagrante sendo levado à presença do juiz, este Ihe falará a respeito da Audiência de Custódia, garantindo que o flagranteado esteja sem as algemas (somente determinando o seu uso em casos excepcionais).

Ademais, o juiz dará ciência ao flagranteado sobre o direito que lhe é garantido de permanecer em silêncio e lhe questionará se tomou ciência e se the foi oportunizado o direito de consultar o seu advogado ou defensor, bem como o direito de ser atendido por um médico e o de se comunicar com seus familiares.

Além disso, indagará quais foram as circunstâncias da prisão, questionando-Ihe o tratamento recebido nos locais por onde passou até chegar à Audiência, para que assim possa averiguar a ocorrência de tortura ou maus-tratos. Frise-se que é dever do juiz verificar se houve a realização de exame de corpo de delito. Outro ponto importante que o juiz deve atentar é que não poderão ser formuladas perguntas com a finalidade de produzir prova para a investigação criminal ou ação penal; e por fim, deverá averiguar hipótese de gravidez, ou até mesmo se existem filhos ou dependentes do preso em flagrante, ou se há presença de alguma doença grave.Posteriormente, dará o juiz a palavra ao representante do Ministério Público e à Defesa (nessa ordem), para fazerem perguntas, sem contudo entrar no mérito dos fatos, devendo no final estes requererem: relaxamento da prisão, concessão da liberdade provisória, decretação da prisão preventiva ou a aplicação de outra medida (CONSELHO..., 2017b). 
Após as manifestações do Ministério Público e da Defesa, o juiz decidirá qual medida irá adotar. Se decretar a prisão preventiva o preso em flagrante será encaminhado para o presídio para aguardar o seu julgamento; se optar em conceder liberdade provisória, relaxar a prisão (no caso de tortura ou maus-tratos) ou até mesmo impor uma medida cautelar alternativa da prisão, deverá ser o preso em flagrante prontamente colocado em liberdade, com a expedição do respectivo alvará de soltura, devendo o flagranteado observar os seus direitos, bem como seus deveres.

É importante frisar sobre a existência de um Sistema Eletrônico, chamado "Sistac", que é disponibilizado pelo Conselho Nacional de Justiça, que tem por objetivo facilitar a coleta de dados produzidos pela Audiência de Custódia a todas as unidades judiciais responsáveis por realizar tais audiências. E é por meio desse Sistema que podem ser analisados os efeitos e os impactos trazidos pela Audiência de Custódia, que podem ser mensurados por intermédio de estatísticas acerca da quantidade de presos em flagrante, analisando-se quantos destes tiveram relaxamento de prisão ou concessão de liberdade provisória, bem como em quais casos as prisões em flagrante foram convertidas em preventivas (CONSELHO..., 2017a).A Audiência de Custódia surgiu na prática no ano de 2015, primeiro sendo aderida pelo Estado de São Paulo, e só depois os outros estados a adotaram. No gráfico a seguir, trazido pelo CNJ no ano de 2016, observa-se o momento em que foi instituída a Audiência de Custódia em cada Estado, e também a economia que ela tem gerado para o país.

Gráfico 6 - Economia trazida pela Audiência de Custódia em cada Unidade da Federação

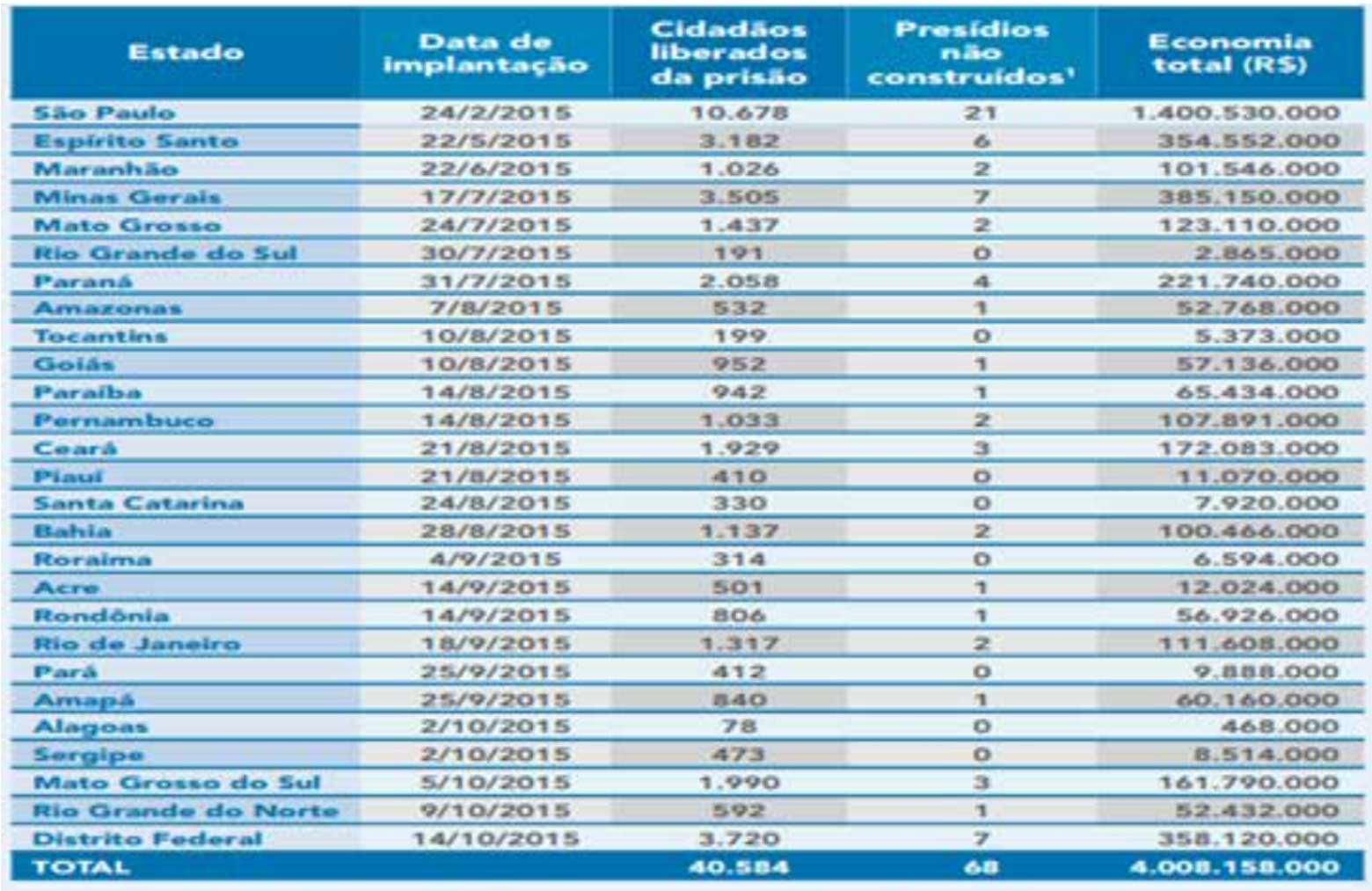

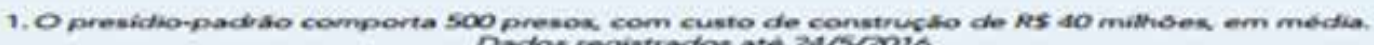
Dados regintrados ate 2.15/2016.

Fonte: CONSELHO..., 2017a. 


\section{Democracia}

Fazendo-se um estudo e uma análise de dados, percebe-se que a Audiência de Custódia tem cumprido com sua finalidade principal, que é corroborar na diminuição de decretações de prisões preventivas, além de contribuir para a economia dos gastos públicos, que tanto vem afetando a realidade financeira do país.

\section{Audiência de Custódia em Petrolina - PE}

Por meio dos dados apresentados anteriormente, constata-se que a Audiência de Custódia foi instaurada no Estado de Pernambuco no ano de 2015, porém cabe salientar que a instalação não ocorreu no Estado como um todo, haja vista que na cidade de Petrolina essa Audiência somente começou a ser realizada no mês de agosto de 2016, segundo informações colhidas no Fórum da referida Comarca.

É mister elucidar que mesmo com pouco tempo de efetivação na cidade de Petrolina, a Audiência de Custódia tem trazido resultados satisfatórios no combate à superlotação carcerária.

Ressalte-se que a Penitenciária Dr. Edvaldo Gomes possui um número reduzido de presos provisórios, se comparada com as estatísticas de presos provisórios no Estado de Pernambuco, e até mesmo no Brasil. A PDEG conta atualmente com 212 presos provisórios, e esse número reflete a eficiência da Audiência de Custódia no cumprimento de sua finalidade.

É importante observar as estatísticas entre os meses de agosto de 2016 até fevereiro de 2017, quanto ao número de flagranteados, analisando-se quantos foram postos em liberdade e quantos foram encarcerados. Vale frisar que nem todos os presos em flagrante são levados à presença de juiz competente, no prazo de até 24 horas, como determina a Resolução, haja vista que muitos flagranteados pagam a fiança, não sendo então necessário o comparecimento à referida Audiência.

Outro ponto a ser observado é que as Audiências de Custódia realizadas na cidade de Petrolina referem-se, também, a presos em flagrante de cidades circunvizinhas. Assim, durante a semana são feitas audiências de presos em flagrante da Comarca de Petrolina, bem como da cidade de Afrânio, contudo cabe salientar que existem os plantões, que abarcam os presos dessas cidades, como das cidades de Cabrobó, Santa Maria da Boa Vista e Lagoa Grande, todas localizadas no sertão de Pernambuco.

Tabela 4 - Dados sobre a Audiência de Custódia na Comarca de Petrolina - PE

\begin{tabular}{|l|c|c|c|c|}
\hline Mês & $\begin{array}{c}\text { Audiências de } \\
\text { Custódia entre os } \\
\text { meses de agosto } \\
\text { de 2016 e feverei- } \\
\text { ro de 2017 }\end{array}$ & $\begin{array}{c}\text { Decretação de } \\
\text { prisão preven- } \\
\text { tiva }\end{array}$ & $\begin{array}{c}\text { Concessão de liberdade } \\
\text { provisória com ou sem impo- } \\
\text { sição de medidas cautelares } \\
\text { diversa da prisão/relaxamen- } \\
\text { to de prisão }\end{array}$ & $\begin{array}{c}\text { Quantidade de } \\
\text { flagranteados }\end{array}$ \\
\hline Agosto/2016 & 42 & 21 & 21 & 42 \\
\hline Setembro/2016 & 47 & 29 & 25 & 54 \\
\hline Outubro/2016 & 39 & 29 & 17 & 46 \\
\hline Novembro/2016 & 50 & 30 & 25 & 55 \\
\hline Dezembro/2016 & 33 & 26 & 18 & 46 \\
\hline Janeiro/2017 & 18 & 3 & 15 & 18 \\
\hline Fevereiro/2017 & 50 & 35 & 28 & 63 \\
\hline
\end{tabular}

Fonte: Dados colhidos no Fórum Dr. Manoel de Souza Filho, Comarca de Petrolina-PE

(Audiência de Custódia). Adaptado pelo autor. 
Com base na análise dos dados anteriores, apesar de haver uma discrepância entre os números de flagranteados e a quantidade de Audiências de Custódia realizadas, justifica-se esta diferença pelo fato de que alguns presos em flagrante pagaram fiança, sendo postos em liberdade antes da Audiência ou então em virtude dos custos de deslocamento dos presos de outras cidades à Comarca de Petrolina restou impossibilitada a realização da Audiência de Custódia pelo juiz competente.

É por meio dos dados que se vislumbra que as Audiências de Custódia realizadas até o mês de fevereiro de 2017 proporcionaram a liberdade de 149 flagranteados, ou seja, o juiz competente optou por não converter o flagrante em prisão preventiva, e sim conceder a liberdade, colaborando assim para que a Penitenciária Dr. Edvaldo Gomes, que vem sofrendo também com a superlotação carcerária, deixasse de receber aproximadamente 149 detentos provisórios em seu estabelecimento.

Assim, a Audiência de Custódia possibilita analisar se no caso trazido à presença do juiz far-se-á necessário manter a prisão, haja vista que o encarceramento deve ser a última alternativa adotada, ou seja, somente em casos de necessidade será o flagrante convertido em prisão preventiva.

Cabe salientar, no entanto, que entre as 279 audiências realizadas nos respectivos meses, 173 pessoas foram encarceradas, ou seja, aproximadamente $62 \%$ dos presos tiveram suas prisões mantidas, porém, mesmo diante do dado de $38 \%$ de liberdades concedidas após a instituição das Audiências de Custódia, esses dados mostram-se satisfatórios, haja vista o curto tempo de aplicação do instituto na comarca de Petrolina, que data do ano de 2016.

É fato que a Penitenciária Dr. Edvaldo Gomes ainda encontra-se superlotada, contudo, caso não houvesse a instauração das Audiências de Custódia na Comarca de Petrolina, a situação do estabelecimento prisional poderia ser agravada.

Deste modo, o poder Judiciário de Pernambuco, na Comarca de Petrolina, tem feito um esforço para que as Audiências de Custódia sejam realizadas, a fim garantir ao preso o seu direito conferido pelos tratados internacionais (dos quais o Brasil é signatário), bem como diante da Resolução n. 213 de 2015 do Conselho Nacional de Justiça, efetivando a luta para a redução do cárcere, colocando a perda da liberdade como ultima ratio diante da prática de crimes.

\section{Considerações Finais}

É perceptível pela análise dos dados estatísticos que o sistema prisional brasileiro possui mais presos do que os estabelecimentos conseguem comportar, detectando-se que esse fato ocorre em virtude da cultura do encarceramento, ou seja, colocar a prisão como maneira de resolver todos os males da sociedade, sem levar em consideração que tal fato implicará outros problemas para o sistema prisional, como as constantes rebeliões entre facções nos presídios brasileiros.

Acerca do sistema prisional brasileiro, percebeu-se que este sofreu fortes influências do sistema prisional progressivo, trazendo algumas mudanças do modelo original, tendo em vista que elencou a progressão de regime e o livramento condicional como benefícios diversos, servindo de alternativa ao cárcere. 


\section{Democracia}

Foi somente no ano de 2015 que o Conselho Nacional de Justiça, percebendo que o problema da superlotação carcerária vinha crescendo de forma assombrosa, possibilitou o advento, por meio da Resolução n. 213, da Audiência de Custódia, objetivando que essa medida pudesse contribuir para a diminuição da população carcerária. É imperioso frisar que tal instituto já era disciplinado em tratados internacionais, dos quais o Brasil é signatário, contudo sua prática não era uma realidade, passando a vigorar de fato somente após a referida Resolução.

Pelos dados colhidos no âmbito de estudo da cidade de Petrolina, percebe-se que a Audiência de Custódia em pouco tempo de prática tem trazido resultados satisfatórios, haja vista que cerca de $38 \%$ dos flagranteados que são levados à presença do juiz são postos em liberdade após a referida Audiência, dessa forma diminuindo a população carcerária da Penitenciária Dr. Edvaldo Gomes de forma significativa.

É importante elucidar, no entanto, que a Audiência de Custódia poderia trazer mais resultados satisfatórios caso fosse permitido ao juiz competente, nessa ocasião, já conceder alguns benefícios, como a suspensão condicional do processo, bem como a substituição da pena privativa de liberdade pela restritiva de direito, pois há muitos casos que preenchem os requisitos exigidos para a concessão desses benefícios, porém o preso provisório terá de esperar até que o Juízo agende uma audiência de instrução e julgamento, quando poderia concentrar tais atos nessa primeira Audiência. Dessa forma, poderia ser criado um rol de infrações consideradas de médio porte a fim de que fossem aplicadas as medidas retromencionadas, de forma analógica ao que é realizado nos Juizados Especiais Criminais às infrações de menor potencial ofensivo. A Resolução n. 213, porém, não prevê essa possibilidade e, dessa maneira, apesar de o instituto da Audiência de Custódia ter grande relevância na redução do encarceramento nas prisões do país, ele ainda não é suficiente para solucionar os problemas dos cárceres brasileiros, fazendo assim com que tais prisões se convertam em depósitos humanos, e os direitos das pessoas que se encontram detidas tornem-se cada vez mais violados.

Assim, pode-se concluir que a Audiência de Custódia, no âmbito de estudo da Comarca de Petrolina-PE, tem sido eficaz nesse pequeno período de tempo em que começou a ser posta em prática a partir de agosto de 2016 (dados colhidos de agosto de 2016 a fevereiro de 2017), levando a uma grande expectativa para um futuro próximo. É necessário frisar, no entanto, que essa Audiência isoladamente não pode ser a única salvadora do sistema prisional, pois é preciso um trabalho maior do poder público para melhorar a situação carcerária do Brasil, evitando assim que a dignidade das pessoas encarceradas continue sendo alvo de desrespeito.

\section{Referências}

ANDRADE, M. F. Audiência de Custódia e as consequências de sua não realização. 2015. Disponível em: <http:// paginasdeprocessopenal.com.br/wp-content/uploads/2015/07/Audiencia-de-Custodia-e-as-Consequencias-de-sua-Nao-Realizacao.pdf>. Acesso em: 27 mar. 2017

BITENCOURT, C. R. Tratado de Direito Penal - parte geral. 22. ed. São Paulo: Saraiva, 2016.

BRASIL. Constituição da República Federativa do Brasil: promulgada em 5 de outubro de 1988. Brasília: Senado Federal, 1988. Disponível em: <http://www.planalto.gov.br/ccivil_03/constituicao/constituicaocompilado.htm>. Acesso em: 2 mar. 2017.

Lei de Execuções Penais. Lei no 7.210 de 11 de julho de 1984. Disponível em: <http://www.planalto.gov. br/ccivil_03/leis/L7210compilado.htm>. Acesso em: 2 mar. 2017. 
BRASIL. Código Penal brasileiro - Decreto-lei no 2.848, de 7 de dezembro de 1940.

CAPEZ, F. Curso de Direito Penal, volume 1, parte geral: arts. 10 a 120. 18. ed. São Paulo: Saraiva, 2014.

CONSELHO NACIONAL DE JUSTIÇA (CNJ). Resolução $n^{\circ} 213$ de 2015. Disponível em: <http://www.cnj.jus.br/busca-atos-adm?documento=3059>. Acesso em: 27 mar. 2017a.

. Resolução no 380, de 2015. Disponível em: <http://www.cnj.jus.br/files/conteudo/arquivo/2015/12/1bef24fdb8f133ec9799642d2da25c8f.pdf>. Acesso em: 21 abr. $2017 \mathrm{~b}$.

Audiência de Custódia. Brasília: CNJ, 2016. Disponível em: <http://www.cnj.jus.br/files/conteudo/arquivo/2016/09/0a99a0ab0eb26b96fdeaf529f0dec09b.pdf>. Acesso em: 11 abr. 2017.

DEPARTAMENTO PENITENCIÁRIO NACIONAL (Depen). Infopen (Informações Penitenciárias). 2014. Disponível em: <http://www.justica.gov.br/seus-direitos/politica-penal/documentos/infopen_dez14.pdf>. Acesso em: 5 mar. 2017.

FOUCAULT, M. Vigiar e punir: nascimento da prisão. 41. ed. Tradução Raquel Ramalhete. Petrópolis, RJ: Vozes, 2013.

G1. Rebelião mais violenta da história do RN tem 26 mortos, diz governo. Disponível em: <http://g1.globo.com/ rn/rio-grande-do-norte/noticia/2017/01/rebeliao-mais-violenta-da-historia-do-rn-tem-27-mortos-diz-governo. html>. Acesso em: abr. 2017.

GRECO, R. Curso de Direito Penal. 16. ed. Rio de Janeiro: Impetus, 2014. . Código Penal Comentado. 9. ed. Niterói, RJ: Impetus, 2015.

JESUS, D. E. de. Direito Penal, volume 1: parte geral. 29. ed. rev e atual. São Paulo: Saraiva, 2008.

MIRABETE, J. F. Manual de direito penal, volume I: parte geral, arts. 10 a 120 do CP. 27. ed. rev. e atual. até 4 de janeiro de 2011. São Paulo: Atlas, 2011.

NORONHA, E. M. Direito Penal, volume 1: introdução e parte geral. 38. ed. São Paulo: Saraiva, 2004.

NUCCI, G. S. Prisão e liberdade. 4. ed. rev. e atual. Rio de Janeiro: Forense, 2014.

ORGANIZAÇÃO DOS ESTADOS AMERICANOS (OEA). Convenção Americana Sobre Direito Humanos. San José, Costa Rica, em 22 de novembro de 1969. Disponível em: <https://www.cidh.oas.org/basicos/portugues/c.convencao_americana.htm>. Acesso em: 7 mar. 2017.

ORGANIZAÇÃO DAS NAÇÕES UNIDAS (ONU). Pacto Internacional sobre Direitos Civis e Políticos. Decreto no 592 , 6 de julho de 1992. Disponível em: <http://www.planalto.gov.br/ccivil_03/decreto/1990-1994/d0592.htm>. Acesso em: 7 mar. 2017.

SUPREMO TRIBUNAL FEDERAL. STF inicia julgamento de ação que pede providências para crise prisional. Disponível em: <http://www.stf.jus.br/portal/cms/verNoticiaDetalhe.asp?idConteudo=298600>. Acesso em: maio 2017. 